\title{
Determinants of Expansion Strategies in Public Training Institutions: A Case Study of Kenya Medical Training College
}

\author{
Musango Paul Chandoo ${ }^{1}$ and Dr. Thomas Katua Ngui ${ }^{2}$ \\ Research Scholar ${ }^{1,}$ Professor ${ }^{2}$ \\ Department of Management and leadership \\ The Management University of Africa \\ Kenya
}

\begin{abstract}
This study set out to find out the determinants of expansion strategies in public training institutions: a case study of Kenya Medical Training College. The specific objectives of the study are to: examine the influence of uptake of courses on the success of expansion strategies in the public training institutions; establish the influence of devolution of health services on the success of expansion strategies in the public training institutions; determine the influence of politics on the success of expansion strategies in the public training institutions and; assess the influence of finances on the success of expansion strategies in the public training institutions. It adopted a descriptive survey design. The study focused on 1943 persons (1900 KMTC employees from the 65 KMTC campuses in Kenya and 43 ministries of health employees in the 43 counties that have KMTC campuses). The sample size comprised $10 \%$ of the target population. In this regard, 194 persons were sampled. The study used stratified random sampling techniques to obtain the study sample. In this regard, KMTC officials from 7 departments namely Finance; Procurement; Registrar (academic affairs); Principals of campuses; Human Resource; Administrative Services and Corporate Communications, Public Relations as well as Ministry of Health Officials were proportionately included in the study. Primary data was collected using a structured questionnaires and interviews. Data from questionnaires was cleaned and coded and analysed using the Statistical Package for the Social Sciences (SPSS) version 24. The data was also illustrated using Tables, Charts, and graphs. The findings show that the four study variables influenced the uptake of expansion strategies at KMTC campuses. In this regard, Pearson Correlation shows that there was statistical significant relationship between uptake of courses $(r=.090, p<0.001)$; devolution of health services $(r=0.221, p<0.001)$; politics $(r=0.079, p<0.001)$; and finances $(r=0.075, p<0.001)$ and success of expansion strategies. These findings show that the devolution of health services was the strongest factor that influenced the success of expansion strategies. This was followed by the uptake of courses, politics, and finances in that order. As such, the expansion strategies can only be successful if the college put in place strategies aimed at enhancing the uptake of courses. When intakes of students were high, KMTC campuses could work within their capacities. This could go on to enhance the level of their success since enough finances were generated. Avoiding the negative influences of the devolution of health services and politics also enhanced the success of expansion strategies at KMTC. In this regard, efforts aimed at reducing political patronage as well as interferences of devolved governments in the running of KMTC campuses would enhance the performance of new campuses. Lastly effort aimed at ensuring that new campuses could generate enough financial resources contributed to the level of success of expansion strategies at KMTC.
\end{abstract}

Key Word: Uptake of Courses, Devolution of Health Services, Politics, Finances, Success of Expansion Strategies.

\section{INTRODUCTION}

Most organizations endeavor to expand their operations in response to growing market demands [1]. In most cases, most institutions implement growth, hereinafter also referred to expansion strategies, so as to bring their services closer to their clients. This is usually done through opening of new branches among other strategies. Regrettably, the success of these new branches is not always guaranteed. A strategy is an outline of how a business intends to achieve its goals and objectives. In this regard, the business analyses the market and takes action aiming at filling an evident market gap or expanding its market share altogether. By so doing the business is able to enhance its position in the market [2]. Since entering new markets is not always easy, Porter (1996) asserts that companies rolling out expansion strategies have to ensure that these strategies are well-thought-out and that they can be sustainably implemented while still achieving the required outcomes. This usually calls for enough backup using existing organization's resources and capabilities to exploit and limit threats in the external environment [2].

Expansion is a complex phenomenon which is essential for the survival of an organization. It enhances the achievement of the goals of a business while still augmenting past successes. Expanding a business means putting in place strategies aimed at increasing profits, maintaining existing customers while attracting new ones, maintaining competitiveness as well as improving the financial and market performance of the company [3]. Regrettably, expansion does not always take place easily. According to 
Mintzberg, it can be influenced by myriads of factors in the environment [4]. These include and are not limited to political changes; economic factors, legal and regulatory demands, sociocultural factors and religious factors among others. Johnson and Scholes argue that the success of a strategy is pegged to the ability of an organization to configure its resources to achieve predetermined goals in the markets and to meet stakeholder expectations in a challenging environment [5].

Realizing that the implementation of expansion strategies will be met with challenges, Lewis et. al., argue that the best formulated strategy would be actually worthless if it cannot be implemented effectively [6]. In this regard, the strategy has to be integrated into every process of the organization. This means that the strategy has to be well understood by the employees of the organization and aligned to the overall goal and mission of organization.

Looking at expansion strategies in Germany, Dowling, Schmude and, Knyphausen argue that a badly designed strategy will never achieve its goals [7]. Conversely, a well-designed strategy has to be well implemented. Failure to do so means, that it will falter and cannot achieve the desired goals which would cost the organization tremendously in terms of cost and lost opportunities. In an analysis of organizations in Singapore, Speculand, points that the implementation of most expansion strategies is thwarted by assumptions that the implementation will automatically succeed [8]. In this light, most leaders fail to formulate a framework to guide them and assume that the organization will readily implement the strategy and that employees will just know what to do to actualize the strategy. Historically, however, this has been proven to be a grave assumption. Any institution that does not match its growth strategies with the right implementation scheme will definitely fail.

A study by Rugman and Collinson, found out that numerous European companies exploit the prospects of the European Union (EU) to expand to new markets within the economic block [9]. This usually happens through opening of new branches, undertaking mergers, franchising, and partnerships among other strategies. This is for purposes of enhancing their financial performance among other objectives.

Ofili (2016) in an investigation of internationalization and entry modes into new markets found out about $75 \%$ of European companies expanded to new markets within the EU for purposes of marketing products and services in the bid to obtain more returns overseas. In some instances, companies expanded for purposes of gaining market shares in the new market as well as mitigating the challenges related with increased competition in domestic markets.

Some of the major American companies such as Pepsi Cola and Coca Cola have always employed expansion strategies in order to gain foot prints in international markets. Pepsi Cola came back to the Kenyan market after decades of stopping bottling in the 70s due to tight competition from Coca-Cola [11]. This shows that global companies are always on the lookout for new opportunities in the market place with the aim of increasing sales. Midwa argues that multinational oil companies such as Total often undertook product development strategies aimed at enhancing their market shares [12]. In this regard, they undertook measures aimed at product differentiation so as to respond to "competition, customer needs, market segmentation, and risk of losing business to alternative solutions, health, safety, quality, and environmental considerations." In the Kenyan telecommunications sector, Ikonya found out that growth strategies such as new product creation and differentiation were often employed [13].

Ferrer-Balas et. al., argue that new branches are supposed to continue operating in perpetuity with little support from the mother organization [14]. This stems out of the fact that implementation is usually backed with sufficient resources and tailormade strategies on how their success could be assured. Failure to have such support means that the new branch may not establish itself in the new market, overcome competition or remain sustainable due to intrinsic and extrinsic challenges facing expansion strategies in the context of the new branch. This current study investigates the challenges facing the actualization of the expansion strategies rolled out by training institutions in Kenya.

One of the challenges facing the actualization of expansion strategies in institutions of higher learning in Bangladesh is the lack of proper product (academic course) development strategies [15]. In Dhaka University, for example, failure by the institutions to offer courses that match students' needs imperiled the success of expansion strategies. This also happens in other Asian countries where expansion strategies fail due to instances of skewed enrollment of students in some courses in branch campuses [16]. In Italy, new campuses are often faced with financial sustainability circles in the wake of low student intakes during expansion to new market segments [17]. This demands effort to ensure that the new campuses offer courses that students demand and at affordable costs [18]. Failure to do so could result to the closure of the new campus [19]. As such, the success of expansion strategies is pegged to their responsiveness to market demands.

Tibarimbasa argues that financial sustainability emanating from high enrollment of students is vital to the success of expansion strategies and by extension the survival of new campuses in Uganda [20]. Sufficient finances enables a campus to fulfill its missions and respond to the current challenges in an increasingly complex and global environment [21]. If the new campus does not meet its financial obligations, it could end up failing or closing altogether. Devolution of health services has also been seen a major culprit. The advent of devolution in Kenya resulted to strikes by nurses and doctors for the better part of the year 2016 [22]. Muchomba and Karanja posit that devolution had significantly impacted on adequacy and availability of both financial and human resources in healthcare facilities in Kenya [23]. Since medical training schools rely on public health facilities for practicums, these strikes could affect training processes in such schools. For newly established campuses, this could affect intakes and reduce the sustainability of such campuses.

In other instances, political patronage has also been blamed for the failure of most strategies adopted by the ministry of health. The health system in Kenya is prone to bureaucracy and political patronage, especially in procurement and recruitment. This was exampled by "a protracted stand-off between the national and county governments and the industry players over the management of health services." This greatly affected service delivery in the health sector, including training at KMTC campuses [24]. From the preceding discourse, it is evident that the expansion strategies adopted by training institutions are faced by numerous challenges the world over. These challenges include and are not limited to skewed intake of some courses leading to challenges related to financial sustainability, devolution, politics, and lack of finances. However, no documented study has focused on these challenges at the KMTC. This creates a knowledge gap that need to be filled with systematic studies such as this current study. In this light, this current study investigates the challenges facing the success of expansion strategies in KMTC. 


\section{THE KENYA MEDICAL TRAINING COLLEGE}

The Kenya Medical Training College (KMTC) was established in 1927. The headquarters is located along Ngong Road, next to Kenyatta National Hospital. Offering an array of health courses, the college has attracted trainees from countries such as Uganda, Botswana, Burundi, Tanzania, Namibia, and Southern Sudan among other African countries. Presently, KMTC has custom-made courses that act in response to society's growing health requirements. As a result, about $80 \%$ of Kenya's healthcare workers are a product of the college.

Due to the demand of its certificate, diploma and higher diploma courses, KMTC has expanded to establish 65 campuses scattered in the 47 counties of Kenya. The Auditor-General, Edward Ouko reports that KMTC opened eight new constituent colleges during the years 2013/14, 2014/15 and 2015/16 contrary to Part 4.0 of the Expansion Policy Guidelines section 1 and 3 which states that infrastructure should only be developed after concept paper and proposal in compliance with the KMTC strate gic plan are prepared and approved and source of financing identified [25].

The new colleges are Makueni, Vihiga, Chwele, Kapenguria, Migori, Bomet, Kitale and Nyandarua. "These colleges were not budgeted for in the year when established (2014/15) and the total expenditure of Sh104, 870,201 incurred on the same was not included in the annual expenditure of the year." In 2017, KMTC opened Kuria, Lake Victoria, Chuka, Gatundu, Iten, Kaptumo, Makindu, Molo, Mosoriot, Mwingi, Nyahururu, Rachuonyo, Rera and Othaya colleges. "These constituent colleges were not budgeted for during the financial year and were not included in the annual estimates for 2016/17 contrary to section 12 of the State Corporations Act. This KMTC appetite for rapid expansion could explain the college recent alert over the fall in applications for diploma and certificate courses. KMTC failed to meet its enrollment target following a sharp drop in the number of KCSE candidates scoring the $\mathrm{C}$ and above grade required for college entry. The medical college had raised alerts through MEMO's over the fall in applications for diploma and certificate courses and has launched a marketing plan through students and staff members. This is a departure from past trends where KMTC had to leave out thousands of applicants.

Most of the new campuses lack human resources and basic essential infrastructure like classrooms, Laboratories and IT/Library services. To implement this ambitious expansion strategy, KMTC has entered into memorandums of understanding with county governments. County governments provide the infrastructure and facilities while KMTC provide the faculty, training, and equipment. The MoUs' give-and-take aspect is that KMTC trains 30 per cent of students from the host county in every intake. The drop in student intake or total lack of intake of students in some campuses has brought the need to redistribute staff. The consequences of this are yet to be reported. This current study assesses the challenges facing expansion strategies that give rise to the establishment of these new campuses.

\section{STATEMENT OF THE PROBLEM}

The Kenya Medical Training College (KMTC) has been implementing expansion strategies which has seen it grow from 28 campuses in 2013 to 65 campuses in 2017 located in 43 out of the 47 Counties (KMTC Strategic Plan 2013-2017). However, some of the new campuses were facing unanticipated challenges. To begin with, evidence shows that some KMTC colleges were experiencing a declining number of applications for admission due to a convergence of various unanticipated reasons such as illadvised expansion of campuses in the recent past and; failure to have enough qualified applicants for most sought-after courses among the 18 programmes on offer [24]. Taking the course of Diploma in Pharmacy at Nyeri campus, for example, the total admission for year 2018 was 27 compared to 60 in the year 2016, a drop of 50\%. In this context, the success of the expansion strategies used by KMTC has often been called to question. As at the end of 2018, enrollment at KMTC campuses envisaged a rise in enrollment from 38, 000 in 2017 to 50,000. The institution also sought to increase campuses from 65 to 150 . Although the Department of Finance and Accounting had managed to "improve internally generated revenue collection from Kshs. 2,927,650,737 to Kshs. 2,976,317.975 between December 2017 and December 2018” (KMTC, 2019), the increase of by Kshs $48,667,238$ in revenue collection was not enough to support such ambitious expansion plans against the annual target of Kshs $292,765,073.5$.

Indeed expansion means that 43 counties have a KMTC campus with some having more than one. However, some of these new campuses are also challenged by competition from private and faith-based medical colleges for a limited number of students. This poses financial sustainability challenges despite the fact that expansion was usually supported by well-laid out expansion strategies. As a result, some KMTC campuses are faced with poor service delivery, low revenue with staff being left without enough students to teach and, underutilization of training facilities in many new KMTC campuses. This leads to the question, are these strategies being implemented successfully? If not, what could be the reasons?

Extant literature shows that one of the challenges facing the health sector, under which KMTC falls, is devolution [26]. This is due to the fact that devolution has resulted in medical staff being transferred to county levels hence affecting training, especially where such staffs are involved in training at these campuses. In addition, politics in the operation of the campuses could also be challenging new KMTC campuses. Another challenge could be lack of finances [23]. However, this influence of these challenges on the success of expansion strategies at KMTC has not been studied in any documented study.

\subsection{Objectives}

The study set out to examine the determinants of expansion strategies in public training institutions while the specific objectives were to: examine the influence of uptake of courses on the expansion strategies in the public training institutions with reference to KMTC; establish the influence of devolution of health services on the expansion strategies in the public training institutions with reference to KMTC; determine the influence of politics on the expansion strategies in the public training 
institutions with reference to KMTC and; assess the influence of finances on the expansion strategies in the public training institutions with reference to KMTC.

\subsection{Justification of the Study}

This research would benefit the management of KMTC such as departmental heads and principals of campuses. In this regard, these took into cognizance the determinants of expansion strategies at the institution. As a result, they would be able to put in place measures aimed at addressing any challenges. The outcome of the study would also be of value to policy makers such as ministry of health education officials and the management board of KMTC. This is particularly so since it would aid them develop insights into the need of relevant measures aimed at enhancing the success of expansion strategies adopted by public training colleges. This would enable them initiate and develop policies aimed at ensuring that a good environment is created for the implementation of these strategies.

This study would also benefit academicians, researchers, and students of strategic management. This is particularly so since the finding obtained could contribute to existing knowledge on expansion strategies in public training institutions and provides background information that could be used in future research and further discussions on expansion strategies in these institutions in regard to the Kenyan context.

\subsection{Scope of the Study}

The study focused on the determinants of expansion strategies in public training institutions. It was delimited to the four objectives conceptualized in this study namely the influences of the uptake of courses; devolution of health services, politics, and finances on the success of expansion strategies in the public training institutions. The study specifically focused on KMTC and ministry of health employees in the 65 KMTC campuses in Kenya. In these campuses, management employees drawn from seven (7) departments of KMTC namely: Finance; Procurement; Registrar (academic affairs); Principals of campuses; Human Resource; Administrative Services and Corporate Communications and Public Relations were targeted. In each department, 1 (one) employee was selected for the study.

In addition, the study targeted health directors from the ministries of health of both the national government and the 43 county governments where KMTC campuses are found. Questionnaires were administered to the KMTC employees while the Ministry of Health employees were interviewed. Data was collected between September and October 2019 from KMTC campuses and, Ministry of health employees across the country. The research started in August 2018 and ended in October 2019.

\section{CONCEPTUAL FRAMEWORK}

A conceptual framework describes the relationship between the independent and dependent variables in a research study [27]. The conceptualized relationship of the study variables in this study is presented in Figure 2.1.

In this study, it is conceptualized that success of expansion strategies (the dependent variables) is influenced by uptake of courses; devolution of health services; politics and finances (the independent variables). The joint influence of these variables determines the level to which extension strategies evidenced by quality service delivery; sustainability of campuses and; enough facilities. Uptake of courses was measured by low application levels; lack of quorum and; closure of departments. On its part, devolution of health services shall be measured by staff transfer; high turnover and, restructuring challenges. Thirdly politics was measured by corruption in procurement; corruption in employment and; political interference in management. Lastly, finances were gauged by resources for infrastructure development; resources for research and resources for staff development.

Independent Variables

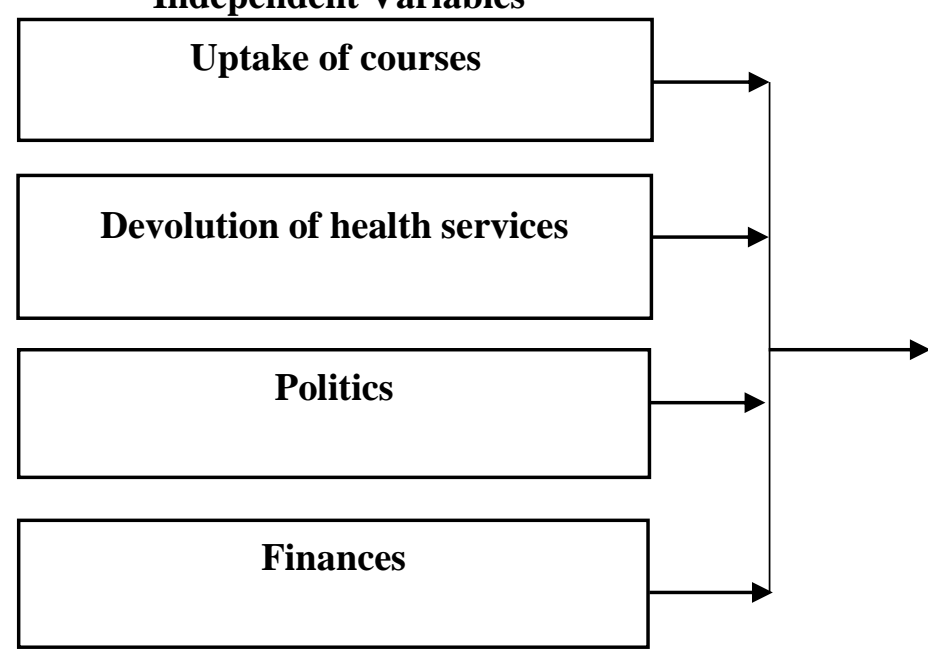

Dependent Variable

\section{Expansion strategies in the Public Training Institutions}

Figure 1.1: Conceptual framework 


\section{LITERATURE REVIEW \\ 5.1 Theoretical Framework}

This study is anchored on the Ansoff Growth Matrix (AGM). Other theories that guide the study are the contingency theory and the theory of customer responsiveness. The Ansoff Growth Matrix casts light on the growth strategies employed by an organization. The matrix was conceptualized by Ansoff in 1965 and posits that business employ four main growth strategies namely: market penetration, market development, product development, and diversification [28]. According to Ansoff, market penetration strategy is "where the organization seeks increased sales for its current products in its present markets through more aggressive promotion and distribution" [28]. Conversely, market development strategy "is where the organization seeks increased sales by taking its current products into new markets." Thirdly, product development strategy is where the organization seeks to grow by serving new customers through the delivery of new products [29]. Lastly, market diversification is where the firm markets new products in new markets. The overall influence of these strategies could lead to sustainability of new KMTC campuses as in the case of this current study in the market.

Indeed, AGM casts light on how expansion strategies employ market penetration strategies and product development strategies such as having courses that are responsive to student needs and how this influences the success of new campuses in public training institutions. In this regard, finances play a pivotal role in ensuring that the new campuses succeed in the new market by supporting product development and diversification.

The contingency theory is based on the assumption that organizational effectiveness is dependent on a fit or match between the type of technology, environmental volatility such as political influence and devolution related challenges as in the case of this study), the size of the organization, the features of the organizational structure and its information system [30]. In this regard, an expansion strategy can only be effective if it responds to the specific needs of a particular institution; new campuses of KMTC in this current study. The contingency theory is not without various limitations [31]. These include Inadequate Literature; it is complex; it is a difficult empirical testing and; it is reactive, not proactive. The contingency theory relates to this study in that it gives managers the flexibility to roll out various growth strategies so as to remain sustainable in the market. However, since it does not stipulate the strategies to use, such flexibility could be curtailed by the challenges facing the application of expansion strategies as in the case of this current study.

The theory of customer responsiveness cast light on how organizations respond to the needs of customers in supply chains. By having a firm understanding of the factors motivating customers to buy a product, it is possible to have strategies that meet those needs in a particular segment in the supply chain [32]. This theory is concerned with the fulfillment of the demands that arise in the market. As such, customer responsiveness entails identification and timely response through appropriate strategies to needs that arise in the market. This theory relates to this current study since growth strategies should be in line with the demands of students in learning processes. In this regard, have courses that are in line with the demands of students could contribute to increased uptake of course by students and vice versa.

Politics also contribute to the performance of organizations. In Kenya for example, political interference with procurement processes is often linked with poor actualization of expansion strategies in health facilities. In addition, politics affects resource allocation to public institutions, which could further challenge the implementation of expansion strategies [23].

\subsection{Empirical Review}

This section presents empirical literature review. This is done in line with the study objectives.

\subsection{Uptake of Courses}

In Bangladesh, Dutta and Islam carried out a study aimed at establishing the responsiveness of higher education to changing job market demand [33]. The study was based on a small-scale empirical study focused on 3 selected social science disciplines of Dhaka University. The study established that lack of proper product (course) development strategies contributed to low enrollment rates in the faculty. In Italy, Bisogno et. al., posit that show that mother campuses were pivotal in securing the successes of their branches by instituting strategies that contributed to increased student intakes and expansion to new market segments among others [17]. Effort was put in place to ensure that the new campuses offered courses that students demanded at affordable costs.

The World Bank study focused on Asian countries show that although most of these campuses tend to attract many applicants, most of the applicants are from particular departments [16]. This leads to low performance of some departments, which may lead to loss of employment by some staff in some of these departments. Kelly et. al. established that new campuses are obligated to fulfill their missions, which needs enough students' uptake of the various departments of the campus [21]. Failure to do so would lead to the collapse or failing of the campuses altogether.

Lingenfelter points out that access to the uptake of the courses deployed by universities is pivotal to the overall enrollment and growth of higher education [18]. Alfaro and Ketels posit that the job market determines the uptake of specific courses on offer in institutions of higher learning [48]. In Uganda, Tibarimbasa argue that financial sustainability, emanating from high student intakes, is vital for the survival of new campuses [20]. In Kenya, a study by Mwebi and Simatwa posit that departments in institutions of learning tended to offer only marketable courses [50].

\subsection{Devolution of Health Services}

By reviewing existing literature, Ansari et. al. show that devolution can lead to increased resource allocation, facilitate greater citizen participation in addressing unique health needs and bolster decision making power at the local levels [34]. Myrna elicits that the effectiveness of training and devolution are connected [35]. 
Oyugi is of the view that the first two years following devolution in Kenya, the vast majority of healthcare workers were showing discontentment with the working conditions, availability of equipment and their salaries and wages [26]. Muchomba and Karanja argue that devolution affected the adequacy and availability of financial and human resources in healthcare facilities in Kenya [24]. Since training at KMTC was interwoven with these healthcare facilities, devolution could thus affect the success of new KMTC campuses. Gimoi established that devolution affected the expansion of health services due to improvement of health infrastructure [36]. Barker et. al. point out that devolution, often coupled with political pressure from the newly elected county governments led to bulk transfer of functions [37]. This often took place without taking cognizance of the counties' level of preparedness.

\subsection{Politics}

Bigsten, Peter and, Mans established that politics affected the implementation of regulatory frameworks, access to finances as well as the work environment for employees [38]. This could go on to affect labour mobility as well as the overall productivity of employees. Yeager, El-Ghali, and Kumar argue that the external political environment in which strategies are implemented affects the level to which they succeed [39].

Arabi et. al. also argue that politics influences the job environment as well as service delivery in the health sector [40]. Kinuthia posits that politics is correlated with service delivery in counties [41]. In some instances, delaying allocation from counties, often as a political strategy, affect the health sector. Furthermore, politics affect personnel which could, in turn, affect service delivery in counties.

\subsection{Financial sustainability}

Bisogno et. al., argue that financial sustainability is a major issue affecting the success of expansion strategies in institutions of higher learning [17]. Bolívar et. al. show the central role played by finances in the sustainability of public institutions [19]. If it goes unchecked, financial unsustainability could result to the closure of the new campus.

A descriptive study by Tibarimbasa posits that financial sustainability is a key determinant of the success of expansion strategies undertaken by institutions of higher learning [20]. Gebreyes established that institutions of higher learning adopted various strategies so as to tap additional financial revenue such as offering their courses in satellite campuses [42]. Matsumura in a study on causes of poor performance in World Bank Water and Sanitation projects in the USA indicate that funding affects the level to which the activities of a project are implemented [43]. Poor performance is thus pegged to inadequate revenue. Organizational performance is thus pegged to financial resources and their utilization. In addition, the study found out that the strategies of the organization could only succeed if they were matched with the right resources.

\section{RESEARCH METHODOLOGY 6.1 Research Design}

The study was based on the descriptive survey design. It adopted the case study approach, which is usually an indepth study of a particular situation [44]; KMTC in the case of this current study. In the descriptive surveys, the study collects data through interviews and questionnaires to samples of individuals among others [45]. In this kind of design, questionnaires and interviews could be used to collect information about people's attitudes, opinions or any of the variety of educational or social issues. In investigating the challenges facing the success of expansion strategies it was deemed a suitable design.

\subsection{Population}

This study targeted KMTC campuses. Presently, KMTC trains health personnel. Currently, KMTC has custom-made courses that act in response to society's growing health requirements. As a result, about $80 \%$ of Kenya's healthcare workers are a product of the college. Presently, KMTC has expanded to establish 65 campuses scattered in the 47 counties of Kenya. KMTC has 1,900 members of staff [46]. The study focuses on these employees. In addition, the study targeted health directors from the ministries of health of both the national government and the 43 county governments where KMTC campuses are found. In each ministry, a director or an assistant director was targeted. This makes 43 individuals. As such, the total targeted study participants shall be 1,943 .

\subsection{Sample}

The sample size comprised $10 \%$ of target population. In this regard, 194 persons were sampled. This is in line with Mugenda and Mugenda who pointed out that a sample size of between 10 and $30 \%$ is a good representation of the target population [47]. The study used stratified random sampling techniques to obtain the study sample. In this regard, KMTC officials from 7 departments namely Finance; Procurement; Registrar (academic affairs); Principals of campuses; Human Resource; Administrative Services and Corporate Communications and Public Relations as well as Ministry of Health officials were proportionately included in the study. These persons were targeted since it is expected that they understand the study subject and that they could adequately represent the study.

\subsection{Data Analysis}

Primary data was collected using a questionnaire and interviews. The collected data was analyzed using the Statistical Package for the Social Sciences (SPSS) version 24. The procedures that were used to test the data include: descriptive statistics (weighted means, percentages, and frequencies) and inferential statistics (Pearson correlation and regression analysis) were used to analyze the data. The findings obtained were presented in Tables and Figures. For open-ended questions, content analysis as 
elicited by White was used [49]. Herein, the findings obtained were described in prose with the emergent meanings being highlighted.

\section{RESULTS AND DISCUSSIONS 7.1 Uptake of Courses}

On the uptake of courses according to psychometric scale statements, the respondents tended to agree to a moderate extent (Weighted Mean of 3) that some of the courses offered by KMTC campuses are not responsive to changing job market demands. This shows that some of the courses offered by KMTC campuses were not reflective of specific market realities which could affect the success of expansion strategies as posited by Alfaro and Ketels [48]. The respondents (Weighted Mean=3) also agreed to a moderate extent that poor course development strategies affect enrollment rates in some departments at KMTC. This corroborates the findings of Dutta and Islam [33]. In the case of KMTC, it is evident that poor course development strategies by KMTC affected the success of expansion strategies in public training institutions.

Also, the respondents tended to agree to a moderate extent (Weighted Mean=3) that KMTC campuses do not have strong mechanisms for ensuring high student intakes for all courses rolled out, with the most of the respondents (21\%), agreeing to a strong extent with the statement. Since it is apparent that there were some mechanisms for supporting the success of the KMTC course rolled out, these findings agree with those of Kelly et. al. that underline the importance of high intake of courses new campuses [21]. The majority of the respondents agreed to a moderate extent, with a Weighted Mean of 3, that there was not a strong effort by new KMTC campuses to offer affordable courses that are highly demanded by students.

The respondents agreed to a little extent (Weighted Mean=2) that poor performing departments in the campus lead to loss of employment by some staff in these departments. This shows that the performance of KMTC campuses was not strongly linked with loss of employment which differs with the report [16] which is of the same position. However, most of the respondents agreed to a great extent (Weighted Mean =4) that low student intake has affected the overall growth and sustainability of some KMTC campuses, which corroborates the findings of Lingenfelter who found out that good uptake of the courses deployed by universities is pivotal to the overall enrollment and growth of institutions of higher learning [18].

The respondents agreed to a moderate extent (Weighted Mean=3) that offering some courses that do not have high earning prospects of graduates challenges the sustainability of some KMTC campuses, which further corroborates the findings of Alfaro and Ketels who linked job market prospects with the success of courses as well as the sustainability of higher learning [48]. Further, the respondents agreed to a moderate extent (Weighted Mean=3) that KMTC campuses do not have strong mechanisms for ensuring high student intakes for all courses rolled out. This could go on to affect the success of new campuses as argued by Tibarimbasa [20].

Lastly, the respondents agreed to a little extent (Weighted Mean =2) that poor performing departments in the campus lead to loss of employment by some staff in these departments. This shows that poor-performing departments did not have strong effect on the employment of some employees as argued by the World Bank [16]. This could indicative of the fact that KMTC was ensuring that most of their departments succeeded by having significant students' intakes.

The respondents, as well as the interviewees, show that students shunned courses they consider not as marketable. This is in agreement with the findings of Alfaro and Ketels who argues that prospects of employment determined the uptake of specific courses on offer in institutions of higher learning [48].

It is also evident that there was inability to obtain enough funding for new campuses. This is in line with the findings of Matsumura who posits that funding affects implementation of projects such as new campuses in the case of this current study. Inability to strengthen the capacities of the existing campuses was also evident [43]. In some cases, there was opening of campuses all over that made people see KMTC as not being a serious institution since some of the campuses were not operating within their potential due to few students. This could go on to affect the financial sustainability of the campuses [17]. In some cases, some of the courses were not affordable which could affect the performance of some departments in the campuses still in agreement with Bisogno et. al. (17). Uptake could be enhanced by offering higher diplomas across all courses that offered basic courses. Lastly, Pearson Correlation shows that there was statistical significant relationship between uptake of courses ( $\mathrm{r}=.090$, $\mathrm{p}<0.001)$ and the success of expansion strategies.

\subsection{Devolution of Health Services}

The respondents agreed to a moderate extent (Weighted Mean =3) that devolution leads to transfer of some doctorslecturers away from campuses, with the majority (33.1\%) agreeing to a very great extent with the statement. This agrees with Muchomba and Karanja who argued that devolution affected the adequacy and availability of financial and human resources in healthcare facilities in Kenya [23]. This could go on to affect the success of new campuses as conceptualized by this current study,

The respondents went on to agree to a great extent (Weighted Mean =4) that it is often hard to run KMTC campuses due to community interference in some counties and; that lack of equipment in some new KMTC has challenged the success of growth strategies employed by KMTC (Weighted Mean =4). This also supports the findings by Muchomba and Karanja that also draws a link between resources and success of growth strategies [23].

The respondents also agreed to a great extent (Weighted Mean =4) that poor state of hospitals has challenged the success of growth strategies employed by KMTC and devolution had affected the adequacy and availability of human resources in healthcare facilities which further challenges training at new KMTC campuses as identified by Ansari et. al. (2011) in Pakistan. However, the respondents agreed to a moderate extent (Weighted Mean =3) that devolution had led to poor performance of some KMTC campuses due to discontentment of members of staff working in public hospitals, which was also identified by Oyugi [26] and, that devolution has affected the expansion of health services hence creating avenue for training for students in satellite 
campuses [26]. These findings show that devolution affected access to human resources as well as equipment in health facilities. This could affect training in KMTC campuses which by extension could affect the success of new campuses.

The respondents and interviewees were asked to state how devolution affected the success of new KMTC campuses. The findings obtained show that hospitals charge students for attachment that was not happening under the national government under the former constitution. This has increased cost on learners. As a result, it is more expensive to offer learning in new KMTC campuses which affects their success as argued by Bolíva et. al. [19].

KMTC campuses also face interference from the office of governor and from politicians especially MCAs. There is also arm-twisting of principals of new campuses to work in a certain way because the majority of new campuses were built by county government. This affects the way the campuses operate and may affect their success. This agrees with Muchomba and Karanja who elicit that devolution affected public institution such as KMTC [23].

Some counties have sponsored the construction of buildings and bought equipment which has promoted expansion of KMTC through new campuses. There also instances in which some counties did not allow seconded staff to work at some KMTCs. In some instances, there was disagreement between county government and KMTC management on land allocation for expansion while in some counties the fee charged hindered students learning. Since resources such as land were vital in expansion processes [5], such disagreement could affect the performance of KMTC campuses.

Devolution also led to job creation for KMTC graduates hence need to train more medical personnel. There was also non-sustainability of the health facilities due to lack of resources like health workers, equipment and supplies which affected the success of health facilities. This further agrees with Johnson and Scholes [5] who posited that resources affected the implementation of strategies. Lastly, regular strikes by public hospital workers negatively influence KMTC training.

Furthermore, Pearson Correlation shows that there was statistical significant relationship between devolution of health services $(\mathrm{r}=0.221, \mathrm{p}<0.001)$ and the success of expansion strategies.

\subsection{Politics}

The respondents agreed to a moderate extent (Weighted Means=3) to all the statements presented to them. To this end, the respondents agreed to a moderate extent that protracted standoff between the national and county governments over the management of health services has had negative influences on service delivery in the health sector as well as in KMTC campuses and that the regulatory environment, which is often subject to the prevailing politics, had often affected the expansion strategies adopted by the KMTC campuses. These findings are in agreement with those of Keillor et. al. [51]. As such, it can be concluded that the political environment could affect KMTC campuses since training on these campuses is linked with public healthcare facilities.

The respondents also agreed to a moderate extent (Weighted Mean=3), that politics had affected access to finances as well as the work environment for employees at KMTC campuses, leading to labour mobility as well as the overall productivity of employees and that the external political environment in which expansion of KMTC campuses takes places affected the level to which these campuses succeed. These findings are in line with the findings of Bigsten et. al. [38].

Lastly, the respondents agreed to a moderate extent (Weighted Mean=3) that delaying allocation from counties, often as a political strategy, affected the health personnel who often double as lecturers in KMTC campuses and this limits the success of new KMTC campuses. These findings agree with Kinuthia, who also argues that politics affect personnel, which could, in turn, affect service delivery in counties [41].

The respondents and the interviewees were to state other ways in which politics affected the success of expansion strategies in new KMTC campuses. The responses obtained show that the opening of campuses and courses areas that had no facilities just to have a KMTC to increase political mileage for the leader in those areas, affected in the quality of training. In some instances, politics made KMTC open colleges that were not its plan as a token to politicians without assessing the liability of such colleges. Campuses were often affected with political patronage for self-interest which agrees with Momanyi who highlighted the negative influences of patronage in service delivery [24].

The expansion was also affected with fear of not establishing a campus in a County due to few of challenges in control due to conflicting interests of the campus by county or national governments. This also agrees with Momanyi who posits that "a protracted stand-off between the national and county governments and the industry players over the management of health services" greatly affected service delivery in the health sector, including training at KMTC campuses [24].

Political appointment of staff working at KMTC had created negative attitudes towards the staff by students. Also, political influences affected the setting up of new KMTC Campus which led to some new campuses not being opened. In some cases, some communities insisted that the institutions should be headed by people from their own communities. This also agrees with Momanyi who reported the negative influences of political patronage in recruitment processes [24].

On its own, Pearson Correlation shows that there was statistical significant relationship between politics ( $\mathrm{r}=0.079$, $\mathrm{p}<0.001)$ and the success of expansion strategies.

\subsection{Finances}

The last objective of the study was to assess the influence of finances on the success of expansion strategies in public training institutions. The respondents had mixed reactions regarding the influence of finances on the success of expansion strategies in public training institutions. To begin with, the respondents agreed to a great extent (Weighted Mean=4) that financial sustainability was a major issue affecting the success of expansion strategies at KMTC campuses, with the majority (36.5\%) agreeing with the statement to a very great extent. These findings agree with Bisogno et. al. who argue that "financial sustainability is a major issue affecting the success of expansion strategies in institutions of higher learning" [17]. 
However, the respondents agreed to a moderate extent (Weighted Mean=3) to all the other statements presented to them. In this regard, the respondents agreed to a moderate extent that financial unsustainability had led to closure of new KMTC departments due inabilities to pay staff as well as to take care of running costs and that; new campuses had often failed to generate enough revenue so as to remain operational in the new market due to poor enrolment of students. These findings agree with those of Tibarimbasa, who argues that "new campuses are obligated to have enough enrolment of students so as to generate enough revenue so as to remain operational in the new market" [20]. The respondents also agreed to a moderate extent (Weighted Mean=3) that poor funding from the government had contributed to poor sustainability in new KMTC campuses and that; inability to attract to funding for research and projects from other sources had challenged the success of newly expanded KMTC campuses which is in line with the findings of Matsumura [43]. These findings thus make it apparent that finances affected the success of growth strategies as posited by this current study.

Lastly, the respondents and interviewees asked to state other ways in which finances affected the success of expansion strategies at KMTC Campuses. The responses obtained show that running a college that had no students or a few students that could have merged with another was a waste of resources. In addition, campuses without enough financial resources show that it was hard to plan and implement projects. These findings also agree with those of Tibarimbasa [20].

Relocation of financial resources to cater for non-core business in campuses also affected the performance of campuses. Lack of finances to employ new staff to work in campuses also affected the success of new campuses. This further agrees with Tibarimbasa who underlines the importance of finances in the implementation of new strategies [20]. Poor funding had led to inadequate classrooms, laboratories and functional libraries in newly established campuses. This corroborates the findings of Bisogno et. al. who established the importance of financial resources in the success of expansion strategies [17]. Lastly, it was pointed out that shortage of finances affected decentralization of some crucial courses due to lecturer's shortage

Lastly, Pearson Correlation shows that there was statistical significant relationship between finances $(r=0.075, \mathrm{p}<0.001)$ and the success of expansion strategies.

\subsection{Success of Expansion Strategies}

The dependent variable of the study was the success of expansion strategies. The findings obtained are presented in the following section. To begin with, the respondents agreed to a great extent that KMTC was very competitive in the health personnel training market in this county with the majority, $42 \%$, agreeing to a very great extent to the statement. The respondents went on to agree to moderate extents (Weighted Means=3) that KMTC campus ran smoothly without any challenges 46.4 and that there were enough facilities at KMTC campus. This shows moderate success of growth strategies as argued by Muchomba and Karanja who sees the presence of enough resources and facilities as indicators of growth strategies [23].

The respondents agreed to a moderate extent (Weighted Mean=3) that all the programmes that KMTC campuses sought to run were all in place and that no department had ever collapsed since we started. This shows the good success of expansion strategies as posited by Kelly et. al. who posits that one of the measures of success of expansion strategies was "the collapse or failure of the campuses altogether" [21]. Lastly, the respondents pointed out that they did not have enough students for all courses offered by the departments on our campus (Weighted Mean of 2, agreement to a very little extent). Based on these findings it is evident that there was mixed evidence of the success of expansion strategies since some of the departments did not have enough students which are, "indicators of a successful campus" as argued by Tibarimbasa [20].

\section{CONCLUSIONS}

The study sought to: examine the influence of uptake of courses on the success of expansion strategies in the public training institutions; establish the influence of devolution of health services on the success of expansion strategies in the public training institutions; determine the influence of politics on the success of expansion strategies in the public training institutions and; assess the influence of finances on the success of expansion strategies in the public training institutions. The findings show that the four study variables influenced the uptake of expansion strategies at KMTC campuses. In this regard, Pearson Correlation shows that there was statistical significant relationship between uptake of courses $(r=.090, p<0.001)$; devolution of health services $(\mathrm{r}=0.221, \mathrm{p}<0.001)$; politics $(\mathrm{r}=0.079, \mathrm{p}<0.001)$; and finances $(\mathrm{r}=0.075, \mathrm{p}<0.001)$ and the success of expansion strategies. These findings show that the devolution of health services was the strongest factor that influenced the success of expansion strategies. This was followed by uptake of courses, politics, and finances in that order. As such, the success of expansion strategies can only be successful if the college put in place strategies aimed at enhancing the uptake of courses. When intakes of students were high, KMTC campuses could work within their capacities. This could go on to enhance the level of their success since enough finances were generated. Avoiding the negative influences of devolution of health services and politics also can enhance the success of expansion strategies at KMTC. In this regards, efforts aimed at reducing political patronage as well as interferences of devolved governments in the running of KMTC campuses would enhance the performance of new campuses. Lastly, effort aimed at ensuring that new campuses could generate enough financial resources can contribute to the level of success of expansion strategies at KMTC. This is due to the fact that enough financial resources and training processes at new campuses, can also contribute to the number of students joining these campuses.

\section{RECOMMENDATIONS}

In the following section, the study recommendations are presented. This is done on the basis of the study objectives. 


\subsection{Uptake of Courses}

There was need to carry out thorough research before rolling out of courses so as to establish the relative importance and demand of the courses that are offered at KMTC. This would enable the enactment of policies that could enhance uptake of all the courses rolled out. The appeal of the courses being offered at KMTC could also be enhanced by hiring enough lecturers and making sure that the courses offered met the expectations of students. Efforts should also be made to ensure that new campuses operated within their capacity before rolling out new ones so as to check wastage of resources. Lastly, there was need to seek enough funding so as reduce the cost of the courses on offer at KMTC.

\subsection{Devolution of Health Services}

There was need at the policy level to ensure that the students were not obligated to pay for attachments so as to reduce the cost of training processes at new KMTC campuses. Mechanisms for reducing interference from politicians needed to be instated through well laid out Memoranda of Understanding between KMTC and political institutions. There is also need for the management of KMTC as well as Ministry of Health officials to establish mechanisms for checking unwarranted influence of KMTC campuses in expansion processes.

\subsection{Politics}

Policy should be instituted by KMTC management to ensure that influence from politicians was averted. Mechanisms for enforcing such policy needs to also be put in place so as to control unwanted opening of campuses and courses in areas that had no facilities through political influences. Specifically, MOU should be implemented between KMTC and County Governments so as to check political influences in the employment of staff or acquisition of land and resources for setting up KMTC campuses. The extent of nepotism and tribal influences KMTC campuses needed to be researched and checked through specially formulated employment quotas irrespective of the counties in which campuses were setup.

\subsection{Finances}

There was need to put enough efforts by the marketing department aimed at enhancing enrollment in all new campuses so as to ensure that enough revenue was generated. Transparency in the allocation of financial resources was necessary so as to check wastage. This could be achieved through specially formulated monitoring and evaluation frameworks. This could also be achieved through policies that emphasized on financial transparency in the finance department. Various fund raising mechanisms needed to be put in place so as to ensure that enough staffs to work in campuses were employed. Collaboration with international funding should also be undertaken by the college management so as to ensure that there was adequate funding for classrooms, laboratories, and functional libraries in newly established campuses.

\section{REFERENCES}

[1] P.M. Omwenga, "An analysis of factors affecting customer satisfaction at Safaricom outlets in Nairobi Central Business District," Thesis, Strathmore University, 2016. Retrieved from http://su-plus.strathmore.edu/handle/11071/4788

[2] Henry, A, Understanding strategic management, New York: Oxford University Press, 2008.

[3] A.A. Thompson, A.J. Strickland, and J.E Gamble, Crafting and executing strategy, 15th Ed.," Boston: McGraw - Hill/Irwin, 2003.

[4] H. Mintzberg, A. Bruce, and L. Joseph, Strategy Safari: A Guided Tour Through The winds of Strategic Management, New Jersey: Prentice Hall, 2005.

[5] G. Johnson, and K. Scholes, Exploring Corporate Strategy, $6^{\text {th }}$ Ed., Prentice Hall: Europe, 2004.

[6] P.S. Lewis, S.H. Goodman, P.M. Fandt, and F.J. Michlistsch, Management: Challenge's for Tomorrow leaders, $5^{\text {th }}$ Edition, Edinburg: Prentice Hall, 2008.

[7] M. Dowling, J. Schmude, and K.D. Aufsess, “Advances in interdisciplinary European entrepreneurship research” LIT Verlag Münster, 2010.

[8] R. Speculand, "Six necessary mind shifts for implementing strategy," Business Strategy Series, 2009, vol.10, Iss. 3, pp. 167172.

[9] A. Rugman, and S. Collinson, Multinational enterprises in the new Europe: are they really global? Kelly School of Business, 2005. Retrieved on May 2, 2019 from: https://core.ac.uk/download/pdf/7080947.pdf

[10] O. Ofili, Internationalization: choosing the right entry mode: lessons from ebay's strategy in china. European Scientific Journal, 2016, vol.12, iss. 1, pp. 202-219.

[11] H. Wangechi, "Pepsi comeback stirs up battle of soft drinks titans." Construction Business Review, 2011, Accessed on May 2, 2019 from: https://www.constructionkenya.com/

[12] J.M. Midwa, Intensive growth strategies adopted by Total Kenya Limited in response to competition in the oil industry in Kenya, MBA Thesis. University of Nairobi, 2008.

[13] M.J. Ikonya, Influence of business strategies on the performance of telecommunication companies in Kenya, MBA Thesis. University of Nairobi, 2015. 
[14] D. Ferrer-Balas, J. Adachi, S.C. Banas, I.Davidson, A. Hoshikoshi, A. Mishra, Y. Motodoa, M. Onga, and M. Ostwald, An international comparative analysis of sustainability transformation across seven universities, International Journal of Sustainability in Higher Education, 2008, vol. 9, Iss. 3, pp. 295 - 316.

[16] World Bank, Skills and research for productivity and growth: higher education in East Asia, Washington, DC: World Bank, 2011.

[17] M. Bisogno, F. Citro, and A. Tommasetti, The financial distress of public sector entities. evidence from Italian public universities, International Journal of Accounting, Auditing and Performance Evaluation, 2014, vol. 10, Iss. 2, $203-227$.

[18] P. Lingenfelter, State Policy Leadership for Higher Education: A brief summary of the origins and continuing evolution of a profession, 2012, retrieved from: http://www.sheeo.org/sites/default/files/publications/STATE\%20POLICY\%20LE ADERSHIP\%20FOR\%20HIGHER\%20EDUCATION_0.pdf.

[19] R. Bolívar, M. Pedro, A. Galera, L. Muñoz, and M. López-Subirés, Risk Factors and Drivers of Financial Sustainability in Local Government: An Empirical Study. Local Government Studies, 2016, vol. 42, Iss. 1, pp. $29-51$.

[20] K.M. Tibarimbasa, Factors affecting the management of private universities in Uganda, Ph.D. Thesis, Makerere University, 2010 .

[21] A. Kelly, M. Schneider, and K. Carey, Rising to the challenge: Hispanic college graduation rates as a national priority, Washington, DC: American Enterprise Institute for Public Policy Research, 2010.

[22] K. Ochieng, "Solve health sector impasse on devolution," Standard Media, 2015, Retrieved on March 8, 2019 from: http://www.standardmedia.co.ke

[23] F. Muchomba, and N. Karanja, "Influence of devolved governance and performance of the health sector in Kenya," The Strategic Journal of Business \& Change Management, 2015, vol, 2, iss. 51, pp. 67-105.

[24] J. Momanyi, "Why KMTC is struggling to attract applicants," Mediamaxnetwork [online], 2018, Accessed on November 11, 2019 from: http://www.mediamaxnetwork.co.ke/opinion/why-kmtc-is-struggling-to-attract-applicants-447682/

[25] E. Mutai "KMTC ignores law to open 14 unbudgeted colleges" [online], Business Daily Africa, 2018, Accessed November 12, 2019 from: https://www.businessdailyafrica.com/economy/KMTC-ignores-law-to-open-14-unbudgeted-colleges/39462344656628-sv7iqfz/index.html

[26] B.O. Oyugi, "Potential Impact of devolution on motivation and job satisfaction of healthcare workers in Kenya: Lessons from early implementation in Kenya and experiences of other Sub-Saharan African Countries," The Journal of Global Health Care Systems, 2015, vol. 5, iss. 1, pp.3-9.

[27] A.G. Mugenda, and O.M. Mugenda, Research methods: Qualitative and qualitative approaches, Nairobi: ACTS Press, 2012. [28] H. Ansoff, Corporate Strategy, New York: McGraw - Hill, 1965.

[29] R. Lynch, Strategic management, $6^{\text {th }}$ Ed., Pearson Education, India, 2009.

[30] G. Reid, and J. Smith, "The impact of contingencies on management accounting system development," Manage. Account. Res., 2000, vol. 11, iss. 4, 427-450.

[31] S. Chand, 4 Limitations of contingency approach management, Your Article Library [online], 2018, Accessed on May 04, 2018 from: http://www.yourarticlelibrary.com/management/4-limitations-of-contingency-approach-management/27906

[32] Gattorna, J. Strategic supply chain alignment, Ed., Gower: Aldershot, 1998.

[33] B. Dutta, and K. Islam, "Responsiveness of higher education to changing job market demand in Bangladesh," Sage Journals, 2017, vol. 4, Iss. 1, 60-81.

[34] U. Ansari, A. Cockcroft, K. Omer, N.D Ansari, A. Khan, U.U. Chaudhry, and N. Andersson, Devolution and public perceptions and experience of health services in Pakistan: linked cross sectional surveys in 2002 and 2004, BMC Health Services Research, 2011, vol. 11, p. 254.

[35] G. Myrna, Recruitment and selection, hiring the right person, SHRM, USA, 2008, 3-8.

[36] T.M. Gimoi, The impact of devolution on health care systems: a case study of Nairobi County health facilities, MBA Thesis, United States International University, 2017.

[37] C. Barker, A. Mulaki, D. Mwai, and A. Dutta, Devolution of healthcare in Kenya: assessing county health system readiness in Kenya: A Review of Selected Health Inputs, Journal of Health, 2014, vol. 1, Iss. 2, pp. 1-8.

[38] A. Bigsten, K. Peter, and S. Mans, "Chapter 10: The Manufacturing Sector,” in (ed.) C. Adam, P. Collier and N. Ndung'u, Kenya: Policies for Prosperity, Oxford University Press and Central Bank of Kenya, 2010, Retrieved from http://www.soderbom.net/Kenya_manufacturing_ch10.pdf

[39] J.L. Yeager, A.H. El-Ghali, and S. Kumar, A guide to the development of an institutional strategic plan. In P.J. Schloss \& K.M. Cragg (Eds.), Organization and Administration in Higher Education, New York, NY: Routledge, 2013, pp. $127-147$.

[40] A. Arabi, F. Rafii, M.A. Cheraghi, and S. Ghiyasvandian, Nurses' policy influence: A concept analysis, Iran J Nurs Midwifery Res, 2014, vol. 19, Iss. 3, 315-322.

[41] M. Kinuthia, Challenges facing devolution in Kenya, Nairobi: Kenyatta University, 2016.

[42] F.M. Gebreyes, Revenue generation strategies in sub-Saharan African universities, PhD Thesis, University of Twente, 2015. 
[43] K. Matsumura Causes of poor performance in World Bank water and sanitation projects, Unpublished Master's Thesis, University of Colorado, Boulde, United States of America, 2008.

[44] R.K. Yin, Doing case study research, $4^{\text {th }}$ ed., Thousand Oaks, CA: Sage, 2009.

[45] D.S Kombo, and D.L Tromp, Proposal and thesis writing: an introduction, Nairobi: Paulines Publications Africa, 2006.

[46] KMTC, July - December 2018 Newsletter, Iss. \#29, Kenya Medical Training College, 2019, Accessed on September 4, 2019 from: https://kmtc.ac.ke/wp-content/uploads/2019/06/KMTC-Newsletter-29th-Edition.pdf

[47] O.M. Mugenda, and A.G. Mugenda, Research, qualitative and quantitative approaches, Nairobi: ACTS Press, 2003.

[48] L. Alfaro, and C. Ketels, Microeconomics of competitiveness: Singapore's higher education aspiration, Harvard Business School, 2016.

[49] H. White, "Citation analysis and discourse analysis revisited," Applied Linguistics, 2004, vol. 25, Iss. 1, pp. 89-116.

[50] B. Mwebi, and E.M. Simatwa, "Expansion of private Universities in Kenya and its implication on quality and completion rate: An analytical study," Educational Research, 2010, vol. 4, iss. 4, pp. 352-366.

[51] B.D. Keillor, W. Hauser, and C.K. Dannemiller, "The "5th p" in marketing: corporate political activity and firm performance: an exploratory study of U.S. firms in the global Marketplace,” Innovative Marketing, 2013, vol. 5, iss. 3, pp. 75-83. 